\title{
New Application of Highly Vesicular Basalt from Jabel Isbil Volcano (Dhamar-Rada'a Volcanic Field), Yemen
}

\author{
M. R. Eraky ${ }^{1, *}$, Mohamed Th. S. Heikal $2, *$ \\ ${ }^{1}$ Physics Department, Faculty of Science, Kafrelsheikh University, 33516 El Geesh Street, Kafr El Sheikh, Egypt \\ ${ }^{2}$ Geology Department, Faculty of Science, Tanta University, Egypt \\ *Correspondence authors: E-mail: moharamderak@yahoo.com \& mohamed.hekal1@science.tanta.edu.eg. \\ Tel.: (+20) 01115985268 ; Fax: (+20) 0473215175 \\ DOI: $10.5185 /$ amlett.2020.021477
}

\begin{abstract}
We address a vesicular basalt sample from Jabel Isbil Volcano that is located in Dhamar-Rada'a Volcanic Field (DRVF), SE Sana'a, Yemen. The studied vesicular basalt represents the main rock type at the top-hill volcano, whereas olivine basalt and mugearite represent the foot-hill and middle-hill volcano, respectively. Therefore, the present investigation stresses on vesicular basalt after thermal treatment processes. Our measurements revealed that the samples have semiconducting behavior with high electrical resistivity, $\rho_{\mathrm{DC}}$. Moreover, the dielectric constant has low/constant values. $\rho_{\mathrm{DC}}$ reached $1.2 \mathrm{G} \Omega . \mathrm{m}$ at room temperature. The authors strongly recommend that the vesicular basalts elsewhere give rise to high economic and strategic potential of high technologies.
\end{abstract}

\section{Introduction}

The Cenozoic volcanic rocks in Yemen (31 to $26 \mathrm{Ma}$ ) [1] have produced four major volcanic fields including the Sana'a Amran (Hamdan Field), Dhamar-Rada'a, MaribSirwah, and Shuqra-Balhaf-Bir Ali Field, which totally cover approximately $2500 \mathrm{~km}^{2}$ [1-3]. Magma emplacement rate, the physic/chemical characterization, rate of degassing, and the tectonic setting characterize each volcanic field based on geo/chronological data. The Isbil Volcano is a part of Dhamar-Rada'a Volcanic Field (DRVF) [4]. The present work represents a comprehensive example of interdisciplinary research work dealing with geology and physics approach as well. Recently, Eraky and Heikal [5] measured electric and dielectric properties on natural Plio-Qaternary basalt of the Hemat Madam Volcano from the foot-middle-hill (olivine basalt and trachybasalt) to top-hill (vesicular basalt) relevant to the Hamdan volcanic field (HVF) without treatment [5]. These measurements showed semiconductor behaviour for the picked sample. Recently, Said et al., studied the same samples of Isbil Volcano on the basis of chemical reactions and their catalysis. They exhibited that these samples, in particular, vesicular basalt, giving rise to an excellent natural catalysis in some chemical reactions [6].

Here, we are eager to investigate vesicular basalt from another locality of the volcanic fields of Yemen. The Jabal Isbil cinder cone of basaltic flows, relevant to DhamarRada'a Volcanic Field (DRVF), is chosen for the present study.

\section{Experimental}

\section{Field aspects and petrographic inspection}

Three major volcanoes, Harras of Dhamar, Jabel Al-Lsi and Hammam-Jabal Isbil which are listed in the "Catalogue of the active volcanoes of the world including solfatara fields" according to either the presence of hot springs of the surroundings of Dhamar [7]. Jabal Isbil volcano under study is located at the western part of Dhamar-Rada volcanic field at the intersections of Lat. $14^{\circ} 35^{\prime} \mathrm{N} x$ Long. $44^{\circ} 40^{\prime} \mathrm{E}$

The geology of the Jabal Isbil represents an inactive volcano of Plio-Qaternary scoriaceous basalt $[\mathbf{1 , 4}$. It was mapped in detail by Chiesa et al. [7].

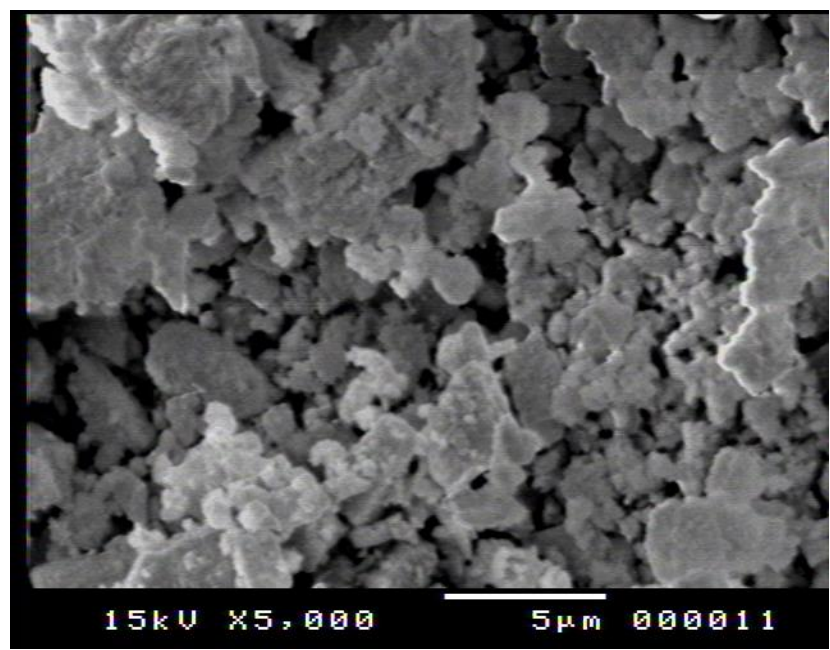

Fig. 1. SEM photograph of vesicular basalt. Note the different shapes of vesicles, mostly drop-like.

Petrographically, almost basaltic lava flows, consist of olivine basalt, mugearite and vesicular basalt. They have vesicular and seriate textures. In the present work, we stress on the vesicular basalts that are located at the top-hill of Isbil volcano. They have vesicular textures (Fig. 1). The groundmass is composed of cluster aggregates of flow plagioclase laths and minor crystals of clino-pyroxene, magnetite and ilmenite. The holes or vesicles form when 


\section{Advanced Materials Letters www. vbripress.com/aml}

gases that were dissolved in the magma come out of solution as it erupts, creating bubbles with respect to a magmatic vapor phase, which accelerates up to the conduit $[8]$.

\section{Mineral and chemical composition}

The mineralogy and chemical composition of the studied rock types of the mafic Isbil Volcano are given in Table 1. These data are quoted from Heikal et al. [4].

Table1. Mineral constituents and their chemical compositions of the studied vesicular basalt from top-hill of Jabel Isbil Volcano [4].

\begin{tabular}{|c|c|c|}
\hline Rock type & $\begin{array}{l}\text { Mineral } \\
\text { constituents }\end{array}$ & Chemical composition \\
\hline $\begin{array}{l}\text { Vesicular } \\
\text { basalt }\end{array}$ & $\begin{array}{l}\text { Ca/plagioclase } \\
\text { and volcano } \\
\text { glass (in major) } \\
\text { and minor } \\
\text { components of } \\
\text { magnetite, } \\
\text { ilmenite } \pm \\
\text { olivine and } \\
\text { clinopyroxene }\end{array}$ & $\begin{array}{l}\text { - Ca-rich plagioclase }=[\mathrm{Ca}, \mathrm{Na} \text {, } \\
\left.\mathrm{Al}_{2} \mathrm{SiO}_{3} \mathrm{O}_{8}\right] \\
\text { - volcanic glass } \\
\text { - Minor components of } \\
\text { magnetite, }\left[\mathrm{Fe}_{3} \mathrm{O}_{4}\right], \text { ilmenite } \\
{\left[\mathrm{FeO}_{\mathrm{TiO}}\right] \pm \text { olivine }[\mathrm{Mg},} \\
\mathrm{Fe}]_{2}\left[\mathrm{SiO}_{4}\right], \text { and clinopyroxene } \\
{\left[\mathrm{Ca}, \mathrm{Na}, \mathrm{Mg}, \mathrm{Fe}^{+2}, \mathrm{Mn}, \mathrm{Fe}^{+3},\right.} \\
\mathrm{Al}, \mathrm{Ti}]_{2}\left[(\mathrm{Si}, \mathrm{Al})_{2} \mathrm{O}_{6}\right]\end{array}$ \\
\hline
\end{tabular}

\section{Material synthesis}

The studied sample was milled to a fine powder in agate mortar automatic machine for $15 \mathrm{~h}$. The powder was compressed into discs $(\approx 3 \mathrm{~mm}$ in height and $10 \mathrm{~mm}$ in diameter) under 75 bars for 5 minutes. Sintering process achieved in the electric furnace at $1050{ }^{\circ} \mathrm{C}$ for $4 \mathrm{~h}$. Bulk density of the sintered discs was determined; it reached $3000 \mathrm{~kg} \cdot \mathrm{m}^{-3}$. The above technique procedures are mostly carried out for preparing the artificial semiconductors. Direct current electrical resistivity, $\rho_{D C}$, was measured by the two- probe technique using electrometer (Keithley model 617). Alternating current, AC, conductivity $\sigma_{\text {tot }}$, and dielectric constant, $\varepsilon^{\prime}$, were measured by the two-probe method using computerized LCR bridge (Model Hioki 3522-50 LCR Hi tester). The details for determination AC and dielectric behavior were reported by Eraky et al. [5].

\section{Results and discussion}

Fig. 2 depicts the DC electrical resistivity ( $\operatorname{Ln} \rho_{\mathrm{DC}}$ ) versus temperature $\left(10^{3} / \mathrm{T}\right)$ over the temperature range from room temperature up to $518 \mathrm{~K}$. It is shown from Fig. 2, there was a gradual decrease in the resistivity with the increase in the temperature. However, the behavior of DC resistivity, $\rho_{D C}$ with temperature for semiconducting materials can be fitted by Arrhenius relation [9]:

$$
\rho_{\mathrm{DC}}=\rho_{0} \exp (\mathrm{E} / \mathrm{kT})
$$

where, ' $\mathrm{E}$ ' is the activation energy, $\rho_{o}$ pre-exponential constant with the dimension $\Omega . \mathrm{m}$, ' $\mathrm{T}$ ' the absolute temperature and ' $k$ ' Boltzmann's constant. From the figure, it is noticed that the sample has high resistivity reached $1.2 \mathrm{G} \Omega . \mathrm{m}$. at room temperature and $0.5 \mathrm{M} \Omega . \mathrm{m}$ at $500 \mathrm{~K}$. This trend considers significant evidence, that the sample under consideration has a semiconducting material character.

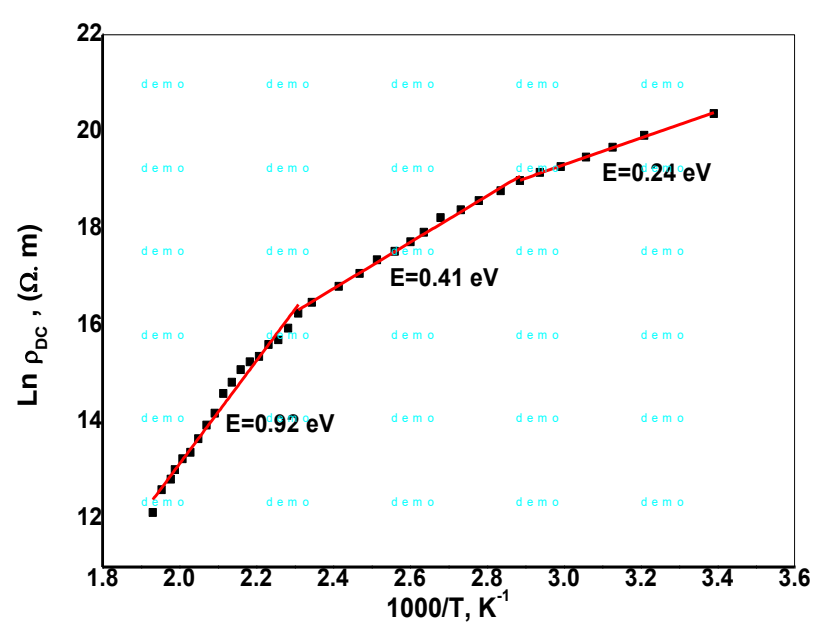

Fig. 2. DC resistivity as a function of temperature for the sintered vesicular basalt.

In general, Fig. 2 shows three distinct regions with different slopes for the curve $\rho_{D C}(T)$. Activation energies for conduction processes are estimated from the slope of the line $\operatorname{Ln} \rho_{D C}\left(10^{3} / T\right)$ according to equation 1 . The $1^{\text {st }}$ region for $\operatorname{Ln}\left(\rho_{D C}\right)$ occur at low temperatures, started from room temperature RT up to $347 \mathrm{~K}$. In this region, the DC resistivity does not exhibit much variation with the rise in temperature; consequently the sample has low DC activation energy $\sim 0.24 \mathrm{e} \mathrm{V}$. DC conduction in this region may be due to the free carriers of impurities, interstitial and types of defects, which appear in the sample at low temperature. The intermediate region started from $347 \mathrm{~K}$ up to $432 \mathrm{~K}$. In this region, the DC resistivity thermally activated, consequently had high activation energy $(\mathrm{E}=0.41 \mathrm{e} \mathrm{V})$. The conduction mechanism in this region is attributed mainly to hopping process for localized charge carriers. $3^{\text {rd }}$ region at high temperature has high activation energy to create and mobile the charge carriers. Therefore, the predominate conduction in this region due to hopping process beside another mechanisms; say polarons mechanism [10].

The conductivity due to alternating current $\sigma_{\text {total }}$, can be expressed by the following relation [11]:

$$
\sigma_{\text {total }}=\sigma_{0}+\sigma_{\mathrm{ac}}
$$

where $\sigma_{0}$ is the frequency independent parameter and can be identified with $\sigma_{\mathrm{DC}}$ as $\omega \rightarrow 0 . \sigma_{\mathrm{ac}}$ is frequency dependent conductivity; follows the universal power law as $\sigma_{\mathrm{ac}}=\mathrm{A} \omega^{\mathrm{S}}$, where $\omega(\omega=2 \pi \mathrm{f})$ is the angular frequency and the parameters ' $\mathrm{A}$ ' and ' $\mathrm{S}$ ' are temperature and frequency dependent [12]. Fig. 3 illustrates the frequency dependence of total AC conductivity $\sigma_{\text {total }}$, for the investigated sample (as $\operatorname{Ln} \sigma_{\text {total }}(\omega)$ vs. Ln F) at fixed temperatures from 313 to $508 \mathrm{~K}$. It is shown from the figure that the AC conductivity enhanced by both the frequency of the applied AC electric field and the temperature. This behavior $\sigma_{\text {total }}(F, T)$ for the sample is similar to that of semiconductors materials. 


\section{Advanced}

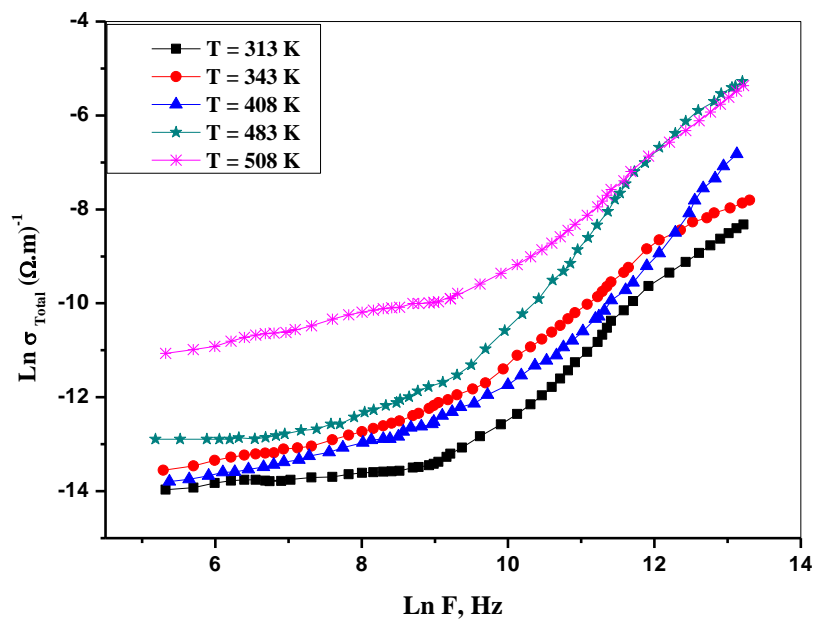

Fig. 3. AC conductivity as a function of AC frequency for the studied vesicular basalt at fixed temperatures.

The illustration of $\varepsilon^{\prime}$ as a function of frequency $\left(\varepsilon^{\prime}\right.$ vs. Ln F) at selected temperatures for the sample is shown in Fig. 4. It is noticed that there was a low dispersion in $\varepsilon^{\prime}(\mathrm{F})$ at low frequencies and temperatures $\leq 483 \mathrm{~K}$ after that $\varepsilon^{\prime}$ remains low/constant value at higher frequencies. At higher temperature $(508 \mathrm{~K}), \varepsilon^{\prime}$ has relatively high value at lower frequencies (reached to $\sim 400$ at $200 \mathrm{~Hz}$ ) after that become low/constant value at a certain frequency. The decreasing in $\varepsilon^{\prime}(F)$ is a normal dielectric trend in semiconductors at low frequencies, this phenomenon related to the formation of heterogeneous structures for the sample [13]. It is reported that there is a strong correlation between the conduction processes and the dielectric behavior for semiconductor materials [14]. Iwauchi and Kharabe et al. reported that there is a qualitative correspondence between the values of conductivity and $\varepsilon^{\prime}$ for semiconductors (i.e. materials with low conductivity have low values of $\varepsilon^{\prime}$ ) [14]. Our results for $\sigma_{\text {total }}(F)$ and $\varepsilon^{\prime}(T)$ reflect this idea (compare Fig. 3 and Fig. 4), which confirm semiconducting behavior for this sample.

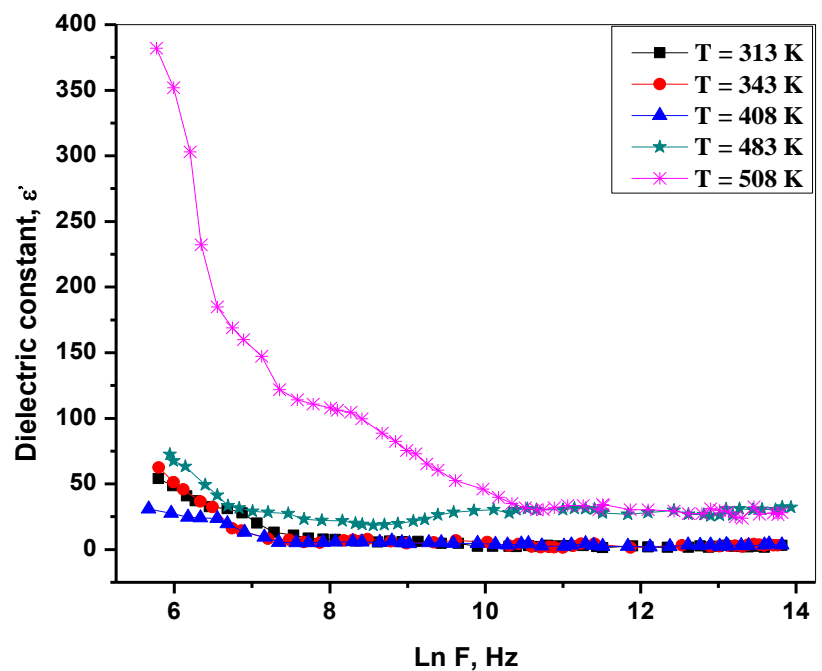

Fig. 4. Dielectric constant $\left(\varepsilon^{\prime}\right)$ vs. frequency ( $\left.\operatorname{Ln} \mathrm{F}\right)$ for the studied sample at fixed temperatures.

\section{Conclusions}

From the foregoing, vesicular basalt of top-hill at Isbil Volcano was sintered at $1050{ }^{\circ} \mathrm{C}$, the final sintered sample has gray color and density $\sim 3000 \mathrm{~kg} \cdot \mathrm{m}^{-3}$. The variation of DC resistivity with temperature reveals the semiconducting behavior for the sample in a wide range of temperature. The sample has relatively high activation energy reached to 0.92 e $\mathrm{V}$ and very high DC resistivity reached $1.2 \mathrm{G} \Omega$.m at room temperature. $\sigma_{\text {total }}(F)$ and $\varepsilon^{\prime}(F)$ measurements indicate the semiconducting character for the sample. Moreover, $\varepsilon^{\prime}$ has low/constant value along the frequency band from $0.1 \sim 1 \mathrm{MHz}$. This value for $\varepsilon^{\prime}$ reached $\sim 20$ at low temperatures. It is clear that the vesicular basalt of the top hill of the Isbil Volcano represents a high potential as natural semiconductors products and these rocks need further studies for being high values in different purposes.

Keywords: Semiconductors, Isbil volcano, electrical properties, dielectrics.

Received: 15 August 2019

Revised: 07 November 2019

Accepted: 23 November 2019

\section{References}

1. Baker, J.; Snee, L.; Menzies, M.; Earth Planet. Sci. Lett., 1996, 138, 39.

2. Mattash, M. A.; Pinarelli, L.; Vaselli, O.; Minissale, A.; Al-Kadasi, M.; Shawki, M. N.; Tassi, F.; Arab. J. Geosci., 2013, 4, 1459.

3. Heikal, M. Th. S.; Lebda, E. M. M.; Orihashi, Y.; Habtoor, A.; Arab. J. Geosci., 2014, 7, 69 .

4. Heikal, M. T. S.; Lebda, EM. M.; Khalaf, E. A.; Arab. J. Geosci., 2019, 12, 723.

5. Eraky, M. R.; Heikal, M. Th. S.; J.A.M.P, 2015, 3, 1610.

6. Said, A. A.; Heikal, M.Th. S.; Guda, M. N.; J. Chin. Chem. Soc., 2019, 66, 725.

7. Chiesa, S.; LaVolpe, L.; Lirer, L.; Orsi, G.; N. Jb. Geol. Palaeontol. Mh. 1983, 8 .

8. Edmonds, M.; Wallace, P. J.; Elements, 2017, 13, 29.

9. Eraky, M. R.; Attia, S. M.; Physica B, 2015, 462, 97.

10. Eraky, M. R.; J. Magn. Magn. Mater., 2012, 324, 1034.

11. Jonscher, A. K.; Nature, 1977, 267, 673.

12. Salami, F.; Giuntini, J. C.; Soulayman, S. S.; Zanchetta, J. V.; Appl. Phys. A, 1996, 63, 447.

13. Koops, C. G.; Phys. Rev., 1951, 83, 121.

14. Iwauchi, K.; Ikeda, Y.; Phys. Status Solidi A, 1986, 93, 309. 